\title{
De la investigación histórica y arqueológica a la divulgación mediante la virtualización
}

\section{Isidro Ot ${ }^{\mathrm{a}}$, Alfred Mauri ${ }^{\mathrm{b}}$ y Josep Socorregut ${ }^{\mathrm{c}}$}

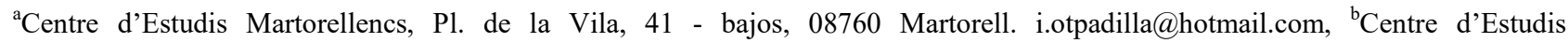
Martorellencs, Pl. de la Vila, 41 - bajos, 08760 Martorell. alfred.mauri@uab.cat y ${ }^{\mathrm{c} S i s t e m e s ~ d e ~ G e s t i o ́ ~ d e ~ P a t r i m o n i ~ S C C L, ~ C . ~}$ Murillo, 17, 08004 Barcelona. josepsoco@gmail.com.

\begin{abstract}
Resumen
Presentamos aquí dos experiencias basadas en la investigación documental y arqueológica, respectivamente, y en el trabajo de divulgación posterior mediante el uso de técnicas y herramientas digitales.

En el primer caso se trata del edificio, retablos y órgano de la iglesia parroquial de Martorell (Barcelona), de los siglos XVI y XVII, destruidos integramente en 1936 en el contexto de la Guerra Civil.

El segundo caso se basa en el estudio arqueológico del monasterio de Sant Genís de Rocafort, situado en el municipio de Martorell y, de forma concreta, en el templo románico, el cual fue objeto de expolio sistemático hasta entrado el siglo XX, lo que provocó la desaparición de partes relevantes del edificio, ya afectado anteriormente por los seísmos del siglo $X \mathrm{~V}$.
\end{abstract}

En ambos casos el trabajo realizado mediante el uso de las tecnologías digitales se ha mostrado de gran utilidad. Desde la perspectiva de la investigación, ha facilitado el proceso de comprensión y análisis de la información y de coherencia del proceso de reconstrucción.

En el ámbito de la difusión ha facilitado la comprensión de una realidad compleja, total o parcialmente desaparecida.

Palabras clave: arqueología, historia, divulgación, virtualización.

\begin{abstract}
This paper aims at presenting two different experiences based on archaeological and documentary research respectively. We also introduce dissemination tasks of basic research by using digital tools and techniques.

Our first case of study focuses on the building, altarpieces and organ located at the parish church of Martorell (Barcelona), dated back to 16th and 17th centuries AD and destroyed completely in 1936 during the Spanish Civil War.

Our second case is based on the archaeological study of the monastery of Sant Genis de Rocafort, also located in Martorell and, particulary, in the Romanesque church. Pillage activities seriously damaged the building until mid-20th century AD. Relevant parts of the church collapsed after the earthquakes occurred in the 15th century just disappeared by vandal action.

In both cases, digital technologies have proved to be useful for research and dissemination. Research activities have benefited from the enhancement of comprehension processes for analysing information and the coherence provided by virtual reconstruction experiences. Within the dissemination domain, general public has been able to better understand a complex reality, total or partially disappeared.
\end{abstract}

Keywords: archaeology, history, dissemination, virtualization. 


\section{Introducción}

El uso de las técnicas y herramientas digitales para la virtualización, en los dos casos que presentamos a continuación, responde a la necesidad de hacer comprensibles al espectador no especializado los resultados de dos procesos de investigación.

Uno correspondiente a la antigua iglesia parroquial de Santa Maria de Martorell, totalmente destruida en 1936, conjuntamente con todo su contenido mueble; otro al monasterio de Sant Genís de Rocafort, fundado a mediados del siglo XI, también situado en el municipio de Martorell. Destaca en este conjunto el edificio de la iglesia monástica, si bien esta fue objeto de un expolio continuado que ha llevado a la desaparición absoluta de la cubierta y el ábside.

Se trata de dos casos distintos pero en los que confluyen la disponibilidad de material fotográfico, en general de buena calidad; la realización de actuaciones de investigación y divulgación, aún cuando en contextos distintos; y la dificultad para transmitir los resultados de la investigación de forma comprensible y amena.

\section{Caso 1: La iglesia parroquial de Santa Maria Martorell}

La iglesia parroquial de Santa Maria de Martorell fue edificada entre 1579 y 1592, momento a partir del cual se inició el proceso que la dotó de diversos retablos, entre los cuales destacan los dedicados a la Virgen del Rosario, al Santísimo y el retablo Mayor. En concreto este último, obra del escultor Agustí Pujol realizado entre 1610 y 1614, es considerado como ejemplo de culminación del retablo renacentista. Cabe hacer mención también de un importante órgano, de autoría desconocida, de 1679 (Clopas, 1960).

En 1936 todos los elementos muebles fueron pasto de las llamas, procediéndose posteriomente, pero de forma casi inmedita, al derribo del edificio. El actual fue construido a partir de 1941 sin conservar ningún elemento del anterior, e incluso, completando la destrucción de la portalada renacentista, restituida finalmente a su emplazamiento original en 1992.

La disponibilidad de fuentes de información gráfica llevó a plantear el uso de la virtualización como mejor forma de presentación.

\subsection{Objetivos}

Se plantearon como objetivos para este caso:

- Dar a conocer el patrimonio constituido por el edificio, retablos y órgano de la iglesia parroquial de Martorell, de los siglos XVI y XVII, destruido íntegramente en 1936.

- Disponer de recursos videográficos para integrar en la exposición Martorell en tiempos de Joan Cererols. Siglo XVII, abierta al público entre noviembre de 2017 y junio de 2018.

- Hacer comprensibles al espectador las imágenes fotográficas disponibles, integrándolas en un escenario realista, sobre una reconstrucción fidedigna.

- Ofrecer una experiencia inmersiva al espectador mediante el uso de gafas de realidad virtual.

\subsection{Las fuentes de información}

El grueso de la información disponible está constituido principalmente por un importante registro fotográfico, de diversos autores y conservado en tres archivos: el Archivo Mas, depositado en el Instituto Amatller de Arte Hispánico; el fondo Salvany, conservado en la Biblioteca de Cataluña; y los fondos del Archivo Fotográfico del Centro Excursionista de Catalunya. Se disponía además de algunas imágenes exteriores publicadas en su momento como tarjetas postales.

El conjunto de imágenes permite una visualización bastante completa del exterior del edificio, si bien más limitada por el lado norte. En cuanto al interior, nos muestran buena parte de la nave principal y de la anexa, correspondiente a la 
capilla del Santísimo, los principales retablos, si bien no cubren la totalidad de las capillas, el órgano y el conjunto y detalles del retablo Mayor.

En cuanto a la información planimétrica, solamente contamos con una planta elaborada por Jaume Amat en 1959, por lo tanto, posterior a la destrucción y construcción del templo actual, publicada por Clopas (1960, p. 9).

\subsection{La elaboración del modelo}

Para la elaboración del modelo se ha utilizado el programa informático Open Source Blender, tomando como punto de partida la planta disponible una vez escalada. La reconstrucción de los alzados se ha guiado por la proporcionalidad obtenida de las imágenes fotográficas, por lo cual no necesariamente se correpsonden con exactitud a la realidad.

Sobre esta base se creó un modelo completo del exterior e interior del edifició para, una vez texturizado siguiendo las pautas que mostraban las fotografias, proceder a la inserción de las imágenes de los elementos muebles (retablos y órgano), a la recreación de algunos elementos ornamentales de mobiliario, objetos litugicos y lámparas, $\mathrm{y}$ algunos personajes a fin de incrementar el realismo.

Completado este proceso se pasó a generar un vídeo con un recorrido exterior e interior, de 2:55 minutos de duración. Este mismo vídeo se generó en formato de $360^{\circ}$ a fin de permitir la visualizarlo mediante el uso de gafas 3D.

Además de Blender, se ha utilizado el programa informático AfterEffects para la edición y montaje final de vídeo.

\subsection{El resultado}

Fruto de este trabajo, como ya se ha señalado, se obtuvo una imagen de vídeo que se incorporó como proyección contínua a los contenidos de la exposición Martorell en tiempos de Joan Cererols. Siglo XVII, realizada con motivo del 400 aniversario del nacimiento en Martorell de este músico del barroco.

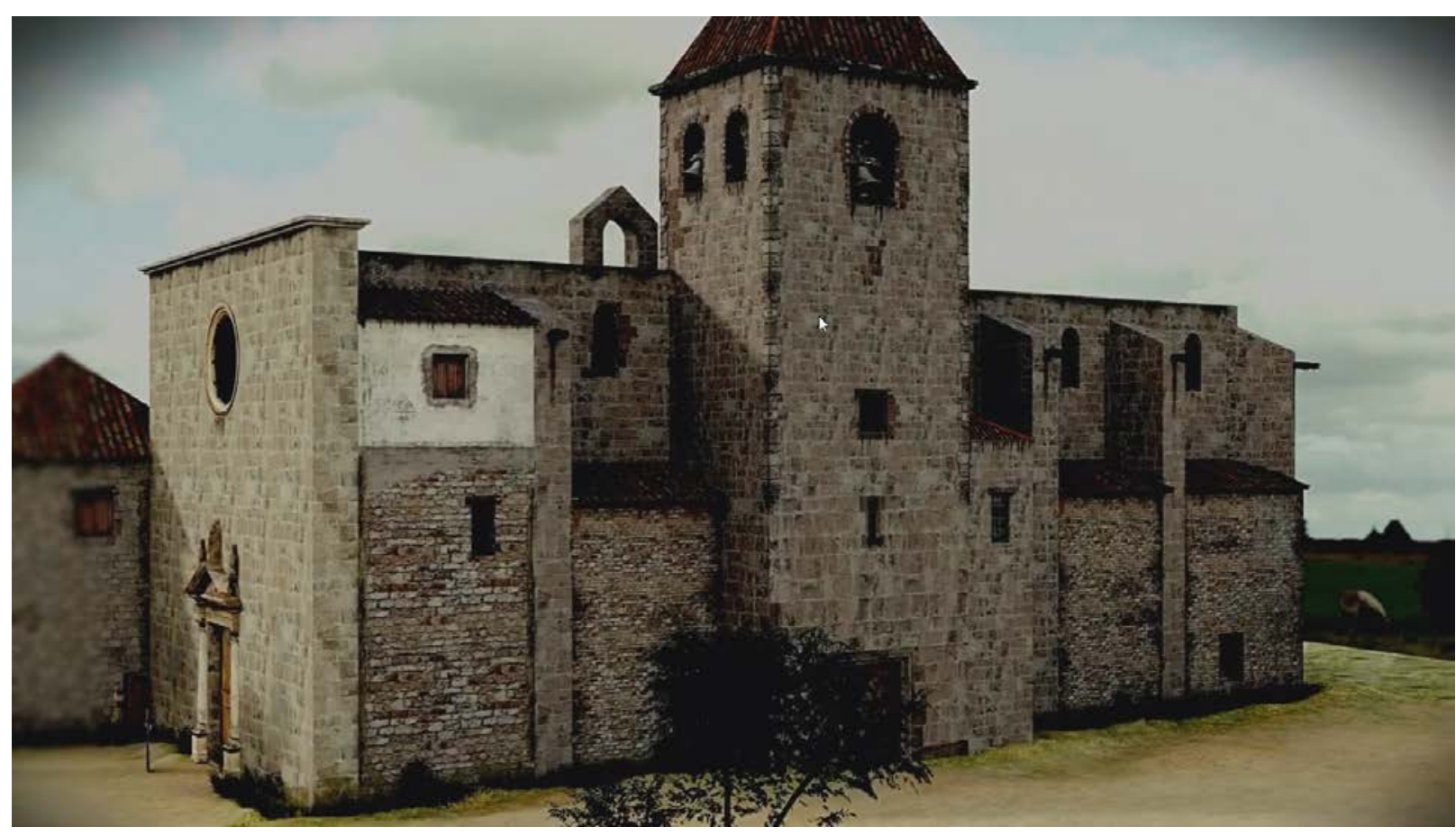

Autor: Isidro Ot

Fig. 1 Restitución del exterior de la iglesia de Santa Maria de Martorell

En paralelo, durante las visitas comentadas a la exposición se invitaba a los participantes a visualizar el recorrido mediante el uso de unas gafas 3D (Oculos Go) dispuestas en la misma sala de exposición.

Este video, del que se muestran dos capturas de pantalla en las figuras 1 y 2, es accesible a través del canal propio de YouTube en el enlace siguiente: https://youtu.be/U1Y631ZsgoU. 


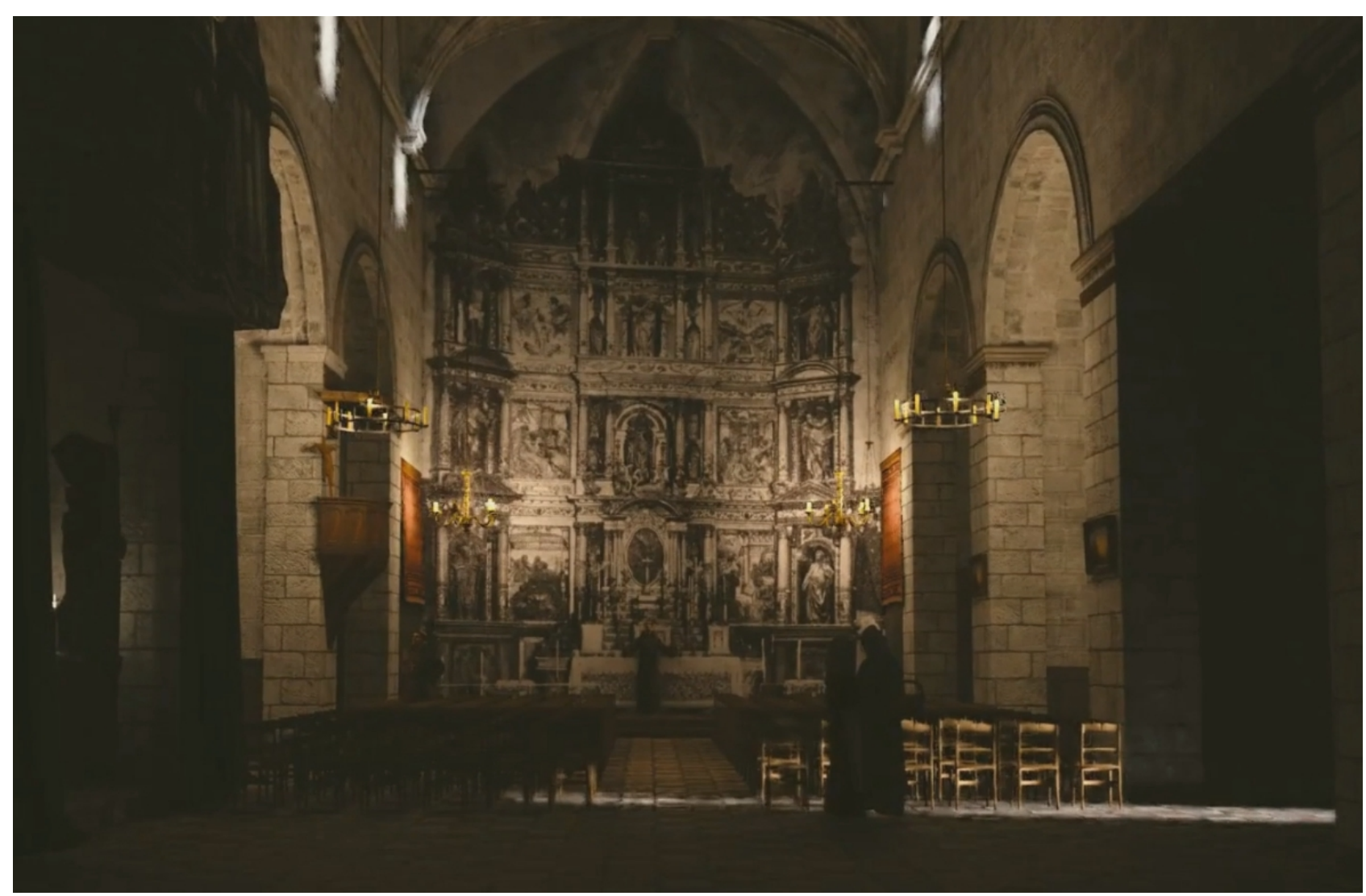

Autor: Isidro Ot

Fig. 2 Restitución del interior de la iglesia de Santa Maria de Martorell, con la imagen del retablo Mayor en su ubicación original

\section{Caso 2: La iglesia del monasterio de Sant Genís de Rocafort}

El monasterior de Sant Genís de Rocafort se encuentra igualmente en el municipio de Martorell. Se trata de un conjunto monástico fundado en el siglo XI del cual subsisten la muralla perimetral, los restos de algunas de las dependencias monásticas, actualmente en proceso de excavación arqueológica, y el edificio de la iglesia, del siglo XII.

El trabajo que presentamos se centra precisamente en este último, el cual ha sufrido importantes mutilaciones. En primer lugar, como consecuencia del terremoto de 1448 el cual provocó la destrucción de la bóveda de la nave y del cimborrio. Como cosecuencia de ello, fue objeto de diversas obras de restauración y transformación durante el primer tercio del siglo XVI, hasta el abandono completo del edificio en una fecha que no podemos precisar, pero que seguramente no va más allà del siglo XVIII. Finalmente, la desamortización de 1835 abrió la puerta a la reutilización de los materiales constructivos del antiguo monasterio, que culminó con la voladura y destrucción del ábside de la iglesia y la parte conservada de la bóveda en 1928 (Baucells, 2007).

En 2010 se inció un proceso de consolidación y estudio arqueológico preliminar, que ha dado lugar, a partir de 2018, al desarrollo de un proyecto de investigación integral que incluye tanto los estudios documentales como arqueológicos. És en este contexto en el que se inscribe este caso.

\subsection{Objetivos}

Los objetivos planteados aquí fueron:

- Dar a conocer el patrimonio constituido por el conjunto monástico de Sant Genís de Rocafort y su historia.

- Mostrar de forma comprensible la estructura original románica del edificio correspondiente a la iglesia monástica 
- Hacer comprensibles al espectador las transformaciones que han llevado al edificio hasta su estado actual, y como se desarrolla el estudio arqueológico del mismo.

- Ofrecer una experiencia inmersiva al espectador mediante el uso de gafas de realidad virtual, más allá de la restitución escenográfica.

\subsection{Las fuentes de información}

Una vez más, afortunadamente, los tres archivos citados en el caso 1 nos han suministrado imágenes del exterior e interior de la iglesia de Sant Genís, anteriores a la destrucción de 1928. Se complementan a su vez con los fondos del Centre d'Estudis Martorellencs y las planimetrías y alzados elaborados a partir de 2010.

A diferencia del caso de la iglesia parroquial de Martorell, aquí la base planimétrica y de alzados ha permitido llevar a cabo el análisis detenido y la documentación de la secuencia constructiva del edificio mediante la aplicación de la metodología propia de la arqueología de la arquitectura, integrando en este proceso la información proporcionada por las imágenes fotográficas. Ha sido a partir de este análisis que se han elaborado las hipótesis respecto a la estructura original de la iglesia románica en el momento de su construcción, propósito inicial del trabajo.

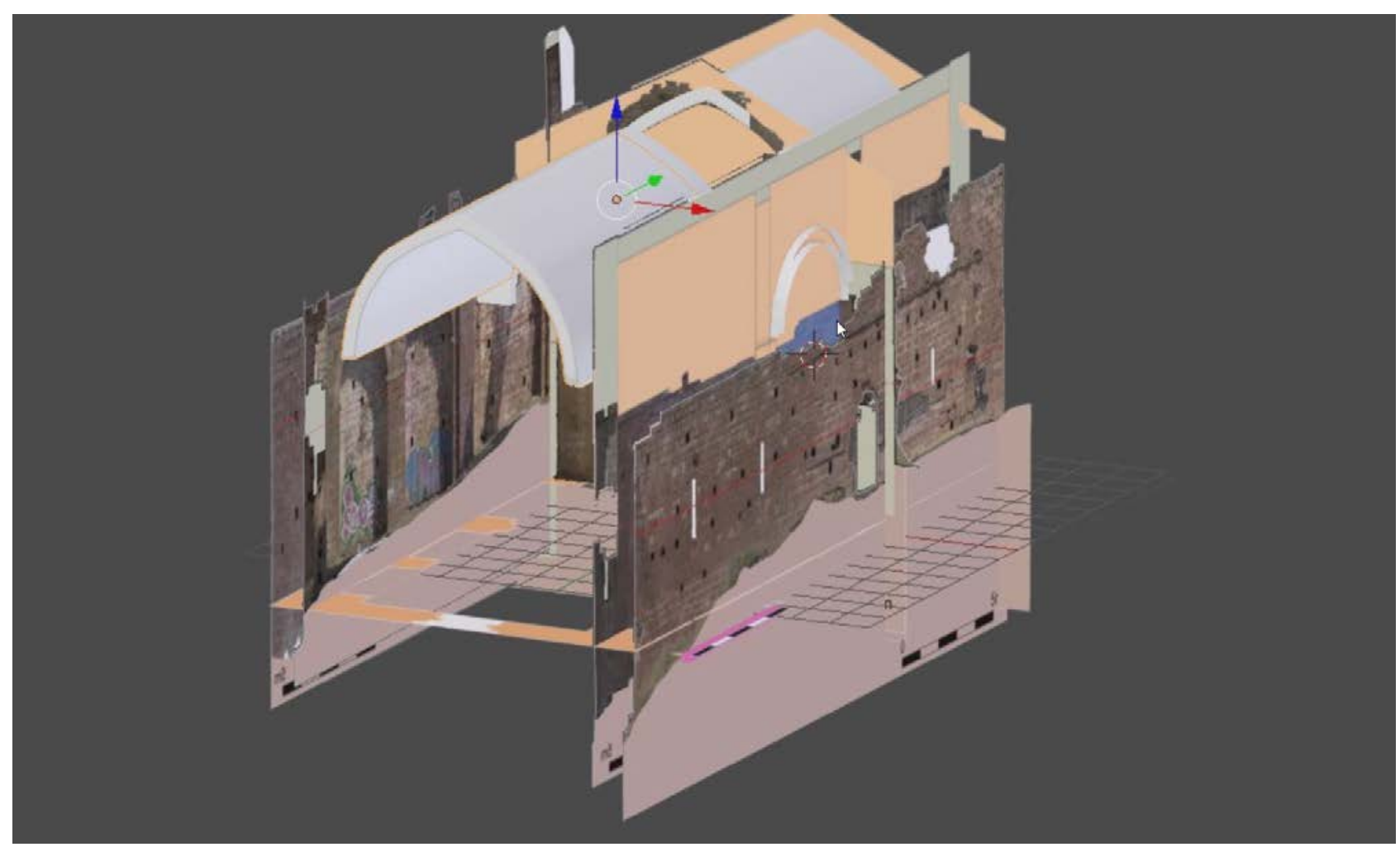

Autor: Isidro Ot

Fig. 3 Proceso de construcción del modelo de la iglesia de Sant Genís de Rocafort a partir de las distintas fuentes de información

\subsection{La elaboración del modelo}

Tanto por el contexto como por las fuestes de información, el proceso de elaboración del modelo presenta algunas diferencias en relación al caso 1. Así, atendiendo a la existencia real de parte de las estructuras (las conservadas hasta la actualidad), se procedió a una cobertura fotográfica completa del interior del templo para generar un modelo fotogramétrico georeferenciado que, una vez procesado, fue debidamente escalado y encuadrado en relación a las bases planimétricas disponibles.

Sobre la base del análisis arqueológico y la hipótesis de reconstrucción, se generaron los elementos ausentes y se restituyeron las partes desaparecidas, procediendo posteriormente al texturizado de las mismas, como se ejemplifica en 
la figura 3. Una vez finalizado el proceso de reconstrucción virtual, se procedió al renderizado de imágenes equiangulares (que posibilitan una visión en $360^{\circ}$ de la escena), tanto del cuerpo central del edificio como de las partes que fueron restituidas, pudiéndolas superponer así en capas durante el proceso de edición.

Finalmente, se integró en escena el narrador que presenta el contexto histórico del monumento, a la vez que describe y señala los elementos restituidos. Para ello la intervención fue previamente grabada en vídeo sobre un fondo croma.

El resultado se presenta como un vídeo de $360^{\circ}$, de 6:41 minutos de duración, apto para su visualización desde un smartphone. Si este dispone de giroscopio, el usuario podrá visualizar el entorno a partir del movimiento del smartphone, todo y que en ausencia de este, es posible girar sobre el escenario tocando sobre la pantalla. Además, el smartphone puede montarse sobre un soporte visual (gafas esteroscópicas) que permiten una mayor immesión.

En este caso, al igual que en el anterior, los programas informáticos utilizados han sido PhotoScan para la elaboración del modelo fotogramétrico; Blender para el modelado, texturizado de las estructuras inexistentes y el renderizado del escenario en su conjunto, y diversos programas de edición de vídeo para el montaje final de la escena, incluida la integración del narrador.

\subsection{El resultado}

El producto ofrece una visión completa del interior de la iglésia de Sant Genís de Rocafort, correspondiente a la obra románica del siglo XII, en el cual aparecen restituidos la ventana de la fachada principal, la bóveda de cubierta de la nave y el cimborrio, visibles sobre los restos originales conservados, como se ejemplifica en la figura 4.

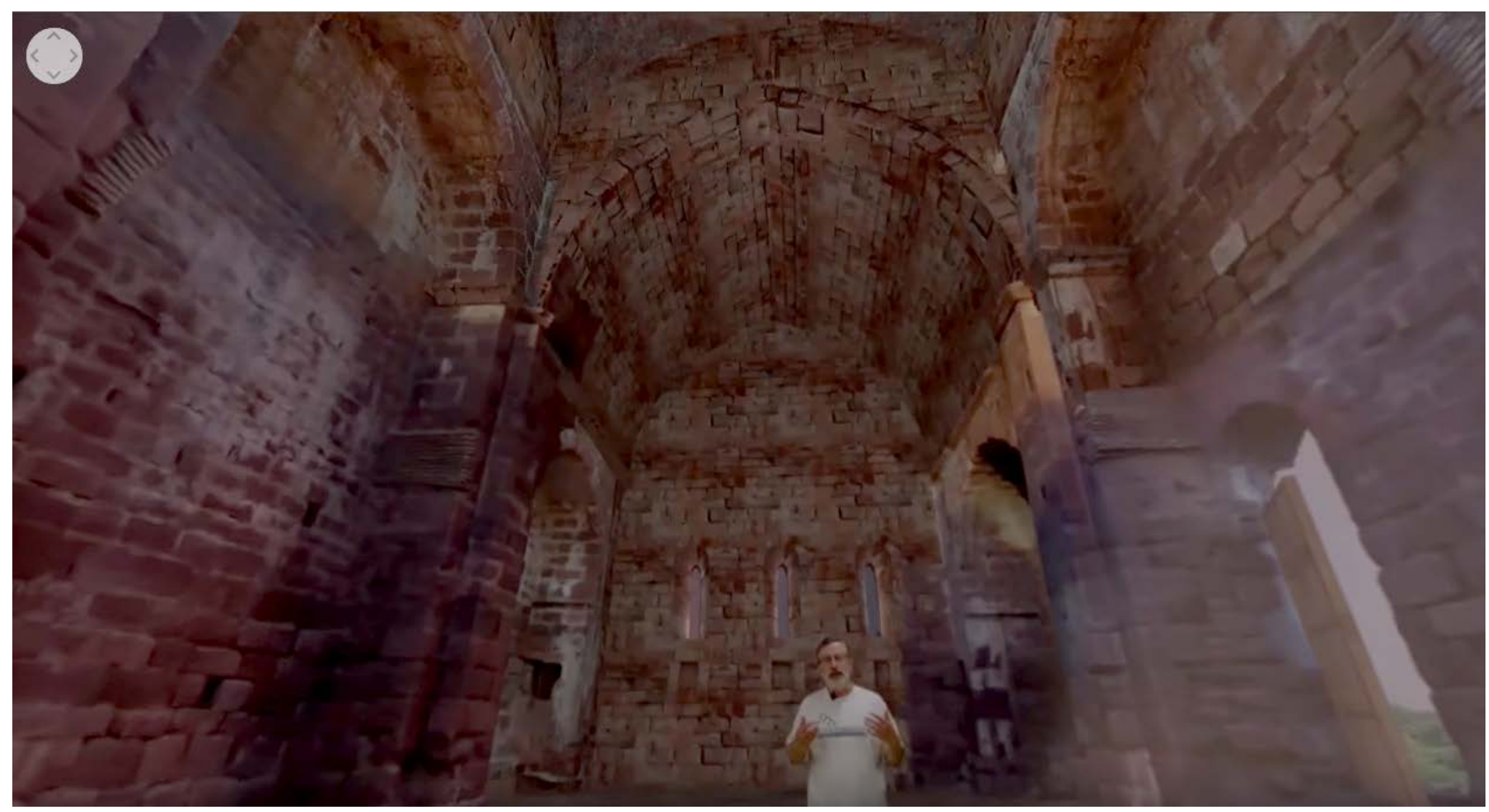

Autor: Isidro Ot

Fig. 4 Captura de un fotograma del vídeo con el narrador con la restitución completa del cimborrio y el ábside de la iglesia de Sant Genís de Rocafort

Este producto final fue presentado durante la jornada de puertas abiertas que lleva a cabo anualmente el equipo de investigación y es accesible, también, a través del canal propio de YouTube a fin de que sea posible su visualización, especialmente, durante las visitas que puedan realizar al yacimiento las personas interesadas, las cuales cuentan, además, con una guía impresa que da acceso a un itinerario de visita autoguiada mediante un conjunto de códigos QR (Mauri, 2015).

Se puede acceder al vídeo del proyecto a través de este enlace al canal de YouTube: https://youtu.be/3VzqPxMkWkw. 


\section{Conclusiones}

Tras ambas experiencias, consideramos satisfactoria la consecución de los objetivos propuestos. Por un lado, hemos podido constatar en el primer caso como el recurso a la virtualización ha permitido, efectivamente, mostrar la iglesia de Santa María de forma que el espectador se forme una idea global del conjunto, superando la simple muestra fotográfica de los retablos y el órgano, así como de la imagen exterior e interior del edificio. Igualmente, en el segundo caso se ha cumplido la expectativa de hacer comprensible la propuesta de restitución, obviando el recurso a la presentación de planos, de más difícil comprensión.

Por otro lado, la experiencia immersiva ha sido satisfactoria, sin que en general se hayan percibido inconvenientes en el uso de recursos digitales immersivos $\mathrm{y}$, en especial, de las gafas 3D, para cuyo uso podría darse un handicap generacional que no hemos observado, si bien fue necesario un cierto acompañamiento inicial.

De ambas experiencias concluimos que la accesibilidad a los recursos tecnológicos hace factible generalitzar el uso de tecnologias digitales y de realidad virtual (immersiva o no) en la difusión del patrimonio, aun cuando es preciso destacar que requieren de una inversión de tiempo elevada para su elaboración.

Finalmente, estas restituciones no solo han aportado facilidad para la difusión del patrimonio, sinó que se han mostrado útiles como instrumento de apoyo a los procesos de estudio, anàlisis y documentación.

\section{Referencias}

Baucells, J. (2007). El priorat de Sant Genis de Rocafort. Martorell: Centre d'Estudis Martorellencs.

Clopas, I. (1960). Notas históricas de la iglesia parroquial de Santa María de Martorell. Martorell: Ayuntamiento de Martorell.

Mauri, A. (2015). Conèixer Sant Genís de Rocafort. Martorell: Centre d'Estudis Martorellencs. 